\title{
RESPOSTAS CONTEMPORÂNEAS A ANTIGOS PROBLEMAS FILOSÓFICOS
}

Franklin Leopoldo e Silva ${ }^{1}$

RESUMO: Nosso objetivo é analisar a historicidade da proposição de perguntas e respostas a "antigos problemas filosóficos". O que nos leva a considerar a questão geral aqui envolvida em termos de filosofia da história: as relações entre tradição e atualidade. É preciso recusar as soluções unilaterais e simplificadoras, como a valorização exclusiva de uma instância em detrimento da outra. A própria história sem progresso, característica da filosofia, indica que a construção das respostas atuais passa pela compreensão crítica das respostas elaboradas na tradição.

PALAVRAS-CHAVE: Filosofia Contemporânea, Filosofia Antiga.

ABSTRACT: Our aim is to analyze the historicity of the proposition of questions and answers to "old philosophical problems". This leads us to consider the general question 
here involved in terms of the philosophy of history: the relations between tradition and current times. It is necessary to reject unilateral and simplifying solutions, such as the exclusive valuation of one instance in detriment of the other. The very history without progress, characteristic of philosophy, indicates that the construction of the present answers passes through the critical understanding of the answers elaborated in the tradition.

KEYWORDS: Contemporary Philosophy, Ancient Philosophy. 
O que o tema me sugeriu deriva de uma interpretação da proposta: entendo que a expressão "respostas contemporâneas" deve significar não propriamente "soluções" atuais para antigas questões, mas sobretudo reelaboração das interrogações que povoaram a tradição, e que foram, elas mesmas, reformuladas em diferentes épocas, obras e autores. Neste sentido, as "respostas contemporâneas" são tão relativas quanto todas aquelas que já foram dadas no passado e que a passagem do tempo distribuiu entre as possibilidades e limites da experiência histórica. Assim, sendo a experiência histórica constituída também pela tarefa de pensar esta experiência, a historicidade é o dado fundamental para qualquer articulação entre o passado e a atualidade no tratamento de problemas filosóficos. A constatação óbvia de que o presente é tão histórico quanto o passado é que permite inserir a experiência de pensar (interrogar, questionar) na transitoriedade, isto é, no núcleo instável da condição humana.

Algumas referências, ou exemplos de como acontecem as reelaborações filosóficas talvez nos ajudem a pensar a questão das relações entre o passado e a atualidade no âmbito da teoria filosófica. Bergson, primeiro exemplo, indica que a gênese da atualidade filosófica está no contato que o filósofo é levado a estabelecer com a consolidação contemporânea da tradição. Isto significa que a 
RESPOSTAS CONTEMPORÂNEAS A ANTIGOS...

consideração do passado e do presente é o primeiro momento da instauração de um novo pensar. E este contato não é tanto com as estruturas das filosofias do passado tomadas em si mesmas quanto com a repercussão deste pensamento no presente do filósofo. Pois será este presente, por suposição em grande parte resultado do passado, que o autor terá de considerar e terá de negar no exercício da liberdade exercida no ato de mudar a forma e o conteúdo do pensamento. Ou seja, a articulação entre o passado e o presente ocorre por via de dois movimentos: 1) a análise cuidadosa e exaustiva da estrutura do pensamento vigente; 2) a negação total deste pensamento que é também a inauguração de outro (negar e transformar estão reunidos na mesma acepção de liberdade). O filósofo nega antes mesmo de saber com relativa clareza o que deverá afirmar, o que está de acordo com a primazia da negação no exercício da liberdade. Estes dois movimentos que instauram o presente filosófico apontam também para o futuro de sua eventual consolidação, de acordo com o ciclo irônico que faz com que muitas vezes a perspectiva crítica de hoje seja o dogma intransigente de amanhã.

Esta relação entre negação e afirmação no percurso histórico das teorias filosóficas não é nova, pois já a encontramos, sob outra forma, em Hegel. Com a diferença de que o movimento dialético, comportando a aufhebung, incorpora na afirmação aquilo que foi negado, conservando 
o passado e transfigurando-o no presente, de modo que a nova perspectiva precisa ser vista como desenvolvimento da contradição intrínseca daquela que é superada. Este processo ao mesmo tempo diferenciado e contínuo é pautado pela racionalidade que ele mesmo revela em seu percurso. Neste sentido, a história da filosofia, ao desvendar as diferentes formas pelas quais a razão examina seus problemas, revela-se a si mesma como a racionalidade do processo histórico, ou seja, o sentido e a finalidade da transformação, cuja principal característica é a de poder ser sempre compreendida em sua gênese e em sua lógica. Este modo de considerar o processo pode ser visto como implicando uma norma, que atua diretamente na lógica do processo, mas que está, antes disso, profundamente entranhada na própria concepção de racionalidade e no teor histórico que a caracteriza. Com efeito, o que significam as mudanças do pensamento que propõem novas respostas a antigos problemas? Para Hegel, isto se chama progresso e é o que define o sentido e a finalidade do processo.

Assim, ao mesmo tempo em que as perguntas e respostas elaboradas em cada época se explicam e se justificam pelo jogo das possibilidades e limites do Espírito Objetivo em termos lógicos e históricos, as passagens e as transformações devem também ser entendida como o progresso que caracteriza a trajetória do Espírito em direção à sua realização absoluta. Neste sentido as "novas respostas" 
não são apenas outras respostas a serem compreendidas em novos contextos, mas sempre aproximações progressivas da verdade absoluta. $\mathrm{O}$ que faz com que o processo de perguntar e responder seja, de um lado, temporal e histórico, mas esteja, de outro, profunda e completamente comprometido com a realização absoluta da filosofia e da história. Em outras palavras, a filosofia é histórica porque o processo histórico de sua efetivação é o caminho para sua realização absoluta.

A propósito, podemos neste ponto lembrar a crítica de Habermas que, dito esquematicamente, se refere à aporia produzida pela posição hegeliana: na medida em que o saber absoluto designa, além do sentido e da finalidade do processo, também o seu fundamento, não há, em Hegel, possibilidade de uma continuidade crítica que faça da filosofia sempre uma filosofia do presente ou da atualidade. Pois a atualização da filosofia e da história significa a sua realização; e o fim no sentido de meta ou objetivo é também o fim como término. ${ }^{2}$

Ora, Foucault nos teria mostrado por via do exame do texto de Kant "Resposta à Pergunta: $O$ que é o Iluminismo?"3 que a filosofia crítica é uma filosofia do presente e, ainda, que o processo do Esclarecimento exige uma filosofia do presente. Pois o esclarecimento é sempre autoesclarecimento: sujeitos esclarecidos pensam-se a si mesmos; épocas esclarecidas refletem sobre si. Por isto, na 
perspectiva crítica, o conhecimento necessita, para se exercer como atividade do sujeito, a elucidação de suas condições transcendentais. Assim na medida em que Hegel ainda conserva a ideia de que a modernidade teria sido fundamentalmente definida por Kant nos termos da unidade entre pensar e compreender os objetos (revolução copernicana), não é pequeno o problema que Hegel cria para si mesmo ao instituir a aporia da simultaneidade entre saber absoluto e crítica como vetor da modernidade. Ao recusar a noção kantiana de limite e adotar a possibilidade da razão absoluta, Hegel teria negado à sua própria filosofia a inserção na perspectiva da crítica da atualidade. Assim a aparente força da filosofia de Hegel, a resposta definitiva e absoluta para todas as perguntas historicamente formuladas, seria também a sua fraqueza, que a colocaria em contradição com a própria modernidade que ela pretendia elucidar. A filosofia de Hegel deixa de ser experiência histórica para ser a realização da totalidade da experiência histórica.

Aprendemos a desconfiar das noções de progresso, sentido e finalidade, principalmente do ponto de vista ético. Mas é perfeitamente possível considerar que a filosofia é uma história sem progresso, o que tem implicações no modo de considerar a possibilidade de "novas respostas" para antigos problemas. Seriam as "respostas contemporâneas" elaborações reflexivas melhores ou mais 
adequadas para responder ou mesmo para "solucionar" questões? Evidentemente, para tratar deste problema teríamos de considerar uma questão anterior: a filosofia se define como a resolução de problemas, podendo ser vista, cartesianamente, como um método em que o pensamento ocorre como cálculo e análise, a partir de modelo matemático? Note-se que a concepção da filosofia como tal modo de pensar significa algo bem próximo à identificação geral entre pensar e calcular ou, pelo menos, entre o rigor do pensar e a exatidão do cálculo.

Se entendermos que a adoção deste modelo implica risco de reducionismo, então seremos levados a optar por uma certa indeterminação inerente à liberdade de pensar, da qual um exemplo conhecido seria a intuição bergsoniana, que no limite seria concebida a partir da oposição entre a exatidão conceitual e a precisão real. ${ }^{4}$ Esta diferença é muito sugestiva e pode ser aplicada ao diagnóstico do processo civilizatório: contamos com meios científicos e tecnológicos dotados de notável exatidão quanto ao que podemos prever a partir deles; nossos fins, ou aquilo que deveríamos realizar através de tais meios, são profundamente obscuros, na medida em que são vistos também pelo critério da exatidão formal e não da precisão das finalidades. A exatidão de nossos instrumentos de viver não nos permite vislumbrar as finalidades da vida com um mínimo de precisão ética. 
$\mathrm{O}$ que evidentemente significa que o progresso material dos meios não corresponde de modo algum ao aprimoramento do discernimento ético-político na relação entre meios e fins. O que nos leva por certo a rever a noção de progresso aplicada à história, se a consideramos pelo aspecto da experiência propriamente humana e não apenas pelo prisma das realizações materiais, acúmulo de bens e incremento das possibilidades técnicas.

No contexto da nossa questão, devemos então entender que, para além do critério de adequação das respostas contemporâneas aos antigos problemas, talvez seja necessário considerar se podemos responder, de qualquer modo, aos problemas que permanecem no horizonte das nossas possibilidades, notadamente, práticas. Talvez seja na esfera da razão prática que tenhamos mais motivos de duvidar acerca da capacidade contemporânea de equacionar as questões que nos afligem, ou pelo menos que deveriam nos afligir, detectando assim o estado de alienação que pode nos impedir de sequer colocar as questões. É sabido que o contexto contemporâneo, por via do pragmatismo, imediatismo, alienação e adaptação cega ao status quo, desvia a consciência de si e do caráter problemático da realidade.

Ora, se não aceitamos inteiramente a ideia de progresso como fio condutor da história, devemos então aplicar grande cautela crítica ao modo como elaboramos 
nossas respostas a questões que já foram ou que vêm sendo formuladas há muito tempo. Ou seja, a articulação entre o passado e a atualidade em história da filosofia depende de uma filosofia da história. Pois tal articulação, se não for pensada filosoficamente, se subordinará de maneira inevitável aos fatos. Isto quer dizer que a teoria, no sentido da palavra que pretende falar do mundo e do sujeito, é ouvida ou lida de maneira indissociável da interpretação. Neste sentido é que devemos entender a afirmação de Sartre: não há fato que não esteja sempre associado a alguma interpretação porque, simplesmente, o mundo é humano e os humanos são seres simbólicos - ou significantes. $O$ equilíbrio necessário à atribuição de significação exclui a crença cega no progresso, como uma tendência a priori que precederia os agentes históricos.

É nesta direção que podemos entender o texto de Benjamin:

"Confiante no infinito do tempo, certa concepção da história discerne apenas o ritmo mais ou menos rápido, segundo o qual homens e épocas avançam no caminho do progresso. Donde o caráter incoerente, impreciso, sem rigor, da exigência dirigida ao presente. Aqui, ao contrário, como sempre têm feito os pensadores, apresentando imagens utópicas, vamos considerar a história à luz de uma situação determinada que a resume em um ponto focal. Os elementos da situação final não se apresentam como 
tendência progressista informe, mas a título de criações de ideias em enorme perigo, altamente desacreditadas e ridicularizadas, incorporam-se de maneira profunda a qualquer presente. (...) Esta situação só é apreensível em sua estrutura metafísica, como o reino messiânico ou a ideia revolucionária, no sentido de 89 ". ${ }^{5}$

A história considerada a partir do progresso implica uma perspectiva genérica e generalista, donde imprecisa e sem rigor, como diz Benjamin. Mas as exigências que fazemos e que nos são feitas a partir do presente em que vivemos supõem situações determinadas no contexto da experiência histórica real. A liberdade do agente histórico é exercida sempre em situação, e este tipo de determinação situacional não contradiz a liberdade, pois é dentro deste contexto que as ideias são criadas, não ao abrigo de um determinismo progressista, mas ao sabor do risco e do perigo, formas da situação histórica. Somente desta maneira tais ideias "incorporam-se de maneira profunda ao presente". E é neste sentido que metafísica, messianismo e revolução podem se associar e constituir impulso verdadeiro da história.

Este texto, quando o aplicamos ao esclarecimento de nossa discussão, indica que as respostas que se sucedem na história diante das interrogações que a cada momento são feitas, não se subordinam a uma trajetória linear de progresso, porque são respostas elaboradas em situações 
determinadas e a partir de exigências históricas contextuais também determinadas. A crença no progresso "necessário" coloca a história sob a direção de uma tendência "informe": ora, é a ação situada que confere forma à história vivida. Assim, a resposta às exigências do tempo como questões historicamente configuradas "incorporam-se a qualquer presente", isto é, são elaboradas no contexto intencional de uma elucidação crítica do presente. E Benjamin não hesita em denomina-las "criações" que se dão em meio a "enorme perigo". O risco que ecoa as palavras de Sócrates no Fédon a respeito da imortalidade: um belo rosco a correr.

Assim, as respostas atuais (em qualquer atualidade) a questões que vêm do passado e se fazem presentes para nós podem ser dadas de várias maneiras e nem todas elas configuram compromisso filosófico, ético, existencial. Podemos ignorar as perguntas; podemos reproduzir as respostas que já foram muitas vezes dadas e podemos tentar correr o risco de enfrentar as perguntas como exigências éticas do presente às quais devemos corresponder. É importante considerar que é o movimento histórico que engendra as questões e que ao respondê-las nos colocamos neste movimento. Perceber a sua direção é apropriar-se de seu sentido. Assim, o futuro não é a "noção" que teríamos de uma etapa da trajetória do progresso do "espírito" em seu percurso lógico-histórico: o futuro será algo engendrado na relação dialética entre as condições objetivas da história e 
as nossas expectativas que tentamos livremente confirmar projetando o porvir.

É por isso que a filosofia se distingue dos saberes que se definem pelo progresso. Este certamente não é o critério para julgar as transformações do pensamento. E, no entanto, é na filosofia que ocorrem as transformações mais profundas na experiência cultural que é dada à humanidade viver. Não apenas pela idade da filosofia, muito superior à da ciência tal como a conhecemos, mas também porque as rupturas são humanamente mais significativas.

Por exemplo, se tomarmos especificamente o período histórico moderno e nele as transformações da subjetividade, constatamos que, de Descartes a Sartre, o que entendemos por $\mathrm{Eu}$, consciência ou sujeito passou por profundas alterações a ponto de nem reconhecermos qualquer realidade na base das diferentes concepções.

Podemos também nos referir às transformações da Ética, e a mais significativa parece ser a crítica da hegemonia da subjetividade na constituição das relações humanas e a proposta de se pensar a ética no contexto da alteridade, conferindo ao Outro uma função bem diversa da tradição, em que a alteridade era sempre considerada a partir da subjetividade. Não há dúvida acerca do alcance e da relevância desta mudança no que se refere ao sujeito moral e aos valores éticos. 
Em ambos os exemplos podemos reconhecer a relação entre novas exigências e novas respostas, sobre um pano de fundo de permanência de questões teóricas e práticas.

Muitos considerariam tais transformações apenas como deslocamentos epistêmicos que ocorrem no conhecimento e nas práticas. Mas é possível afirmar que estes deslocamentos devem ser compreendidos à luz do movimento histórico que mencionamos há pouco. E como a história é feita, inseparavelmente, de fatos e valores, de condições objetivas e subjetivas, essas transformações certamente se relacionam a valores: o que muda é o modo de julgar a realidade e a nós mesmos. E como julgar é a forma mais eminente de pensar, o que está em jogo nas questões e nas respostas, antigas e novas, são as ressignificações do mundo e de nós mesmos que vão ocorrendo no movimento histórico - subjetivação e objetivação no trabalho de pensar a condição humana.

O que nos leva a considerar a questão geral aqui envolvida em termos de filosofia da história: as relações entre tradição e atualidade. É preciso recusar as soluções unilaterais e simplificadoras, como a valorização exclusiva de uma instância em detrimento da outra. Pois a própria história sem progresso, característica da filosofia, como apontamos, indica que a construção das respostas atuais passa pela compreensão crítica das respostas elaboradas na tradição. E também a reposição das questões: pois o modo 
como os autores de outros tempos fizeram suas perguntas nos ajudam a fazer as nossas, como disse Merleau-Ponty. ${ }^{6} \mathrm{E}$ as dificuldades que tiveram, estivessem ou não conscientes delas, para dar conta das questões de seu tempo, nos alertam, a nós que vivemos em tempos porventura mais sombrios, contra qualquer pretensão que vá além da relatividade histórica - isto é, a condição contingente da vida e do pensamento.

\section{NOTAS}

${ }^{1}$ Professor Titular da Universidade de São Paulo (Usp). Doutor em Filosofia pela Universidade de São Paulo (Usp). E-mail: franklin@usp.br.

${ }^{2}$ HABERMAS, J. O Discurso Filosófico da Modernidade. Tradução de Luiz Repa e Rodney Nascimento. Editora Martins Fontes, São Paulo, 2002, cap. 1.

${ }^{3}$ FOUCAULT, M. Qu'est ce que la critique? (Critique et Auklarung). Bulletin de la Socieé Française de Philosophie, vol. 82, no.2, abril/junho de 1990, pgs, 35-63.

${ }^{4}$ BERGSON, H. O Pensamento e o Movente. Introdução I. Tradução brasileira Editora Martins Fontes, São Paulo, 2006.

${ }^{5}$ BENJAMIN, W. A Vida dos Estudantes. Apud. LOWY, M., A Filosofia da História de Walter Benjamin. Revista de Estudos Avançados, USP< vo. 16, n. $45,2002$. 
RESPOSTAS CONTEMPORÂNEAS A ANTIGOS...

6 MERLEAU-PONTY,M. Em Toda Parte e em Nenhuma. Sinais. Tradução brasileira Editora Martins Fontes, São Paulo.

\section{REFERÊNCIAS BIBLIOGRÁFICAS}

BENJAMIN, W. A Vida dos Estudantes. Apud. LOWY, M., A Filosofia da História de Walter Benjamin. Revista de Estudos Avançados, USP< vo. 16, n. 45, 2002.

BERGSON, H. O Pensamento e o Movente. Introdução I. Tradução brasileira Editora Martins Fontes, São Paulo, 2006.

FOUCAULT, M. Qu'est ce que la critique? (Critique et Auklarung). Bulletin de la Socieé Française de Philosophie, vol. 82, no.2, abril/junho de 1990.

HABERMAS, J. O Discurso Filosófico da Modernidade. Tradução de Luiz Repa e Rodney Nascimento. Editora Martins Fontes, São Paulo, 2002.

MERLEAU-PONTY,M. Em Toda Parte e em Nenhuma. Sinais. Tradução brasileira Editora Martins Fontes, São Paulo. 